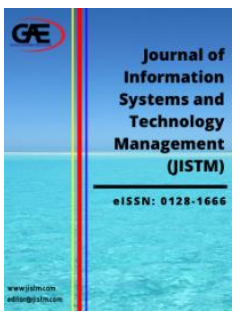

\author{
JOURNAL OF INFORMATION \\ SYSTEM AND TECHNOLOGY \\ MANAGEMENT (JISTM)

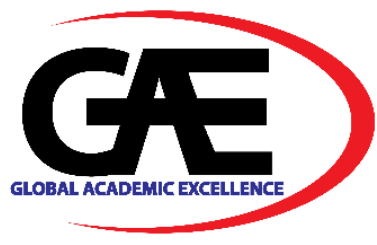

\title{
NETWORK DGPS ACCURACY ASSESSMENT AT WEST COAST PENINSULAR MALAYSIA
}

\author{
Muhammad Farid Mohd Yazair $^{1 *}$, Tajul Ariffin Musa ${ }^{1,2}$, Wan Anom Wan Aris ${ }^{1}$, Ivin Amri \\ Musliman $^{1}$, Abdullah Hisam Omar ${ }^{1}$ \\ 1 Geomatic Innovation Research Group (GnG), Faculty of Built Environment \& Surveying, Universiti Teknologi \\ Malaysia, 81310 Johor Bahru, Johor, Malaysia \\ Email: faridyazair@gmail.com; Email: wananom@utm.my; Email: Ivinamri@utm.my. \\ Email: abdullahhisham@utm.my \\ 2 Centre of Tropical Geoengineering (GEOTROPIK), School of Civil Engineering, Faculty of Engineering, \\ Universiti Teknologi Malaysia, 81310 Johor Bahru, Johor, Malaysia \\ Email: tajulariffin@utm.my \\ * Corresponding Author
}

\section{Article Info:}

\section{Article history:}

Received date: 01.10 .2021

Revised date: 01.11 .2021

Accepted date: 20.11.2021

Published date: 01.12.2021

\section{To cite this document:}

Yazair, M. F. M., Musa, T. A., Aris, W. A. W., Musliman, I. A., Omar, A. H. (2019). Network DGPS Accuracy Assessment at West Coast Peninsular Malaysia. Journal of Information System and Technology Management, 6 (24), 301-311.

\section{DOI: $10.35631 / J I S T M .624028$}

This work is licensed under CC BY 4.0

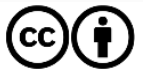

\begin{abstract}
:
Maritime safety of navigation is essential for maritime activities especially when approaching the harbor. One of the important aspects in safety of navigation is positioning accuracy which the accuracy should less than 5 meters as recommended by IALA. Such accuracy can be provided by DGPS services. Nevertheless, the DGPS accuracy is bound to distance-dependent error due to uncorrelated errors between reference and rover station. By implementing the network-based DGPS technique, this issue however can be expected to be improved. This issue can be overcome by implementing the network-based DGPS technique to the positioning method. Hence, multiple of CORS in Peninsular Malaysia and Sumatran Indonesian were utilized to generate the network-based DGPS corrections based on LIM to cover the west coast of Peninsular Malaysia. The single point positioning, DGPS and networkbased DGPS solutions were being compared with known points to determine the reliability of positioning in marine activities. The accuracy shows that the DGPS and network-based DGPS are better compared to single point positioning with below than $15 \mathrm{~m}$ and $20 \mathrm{~m}$ respectively. Meanwhile, the DGPS technique clearly had shown the distance-dependent error propagation in positioning. This paper presents on the accuracy and efficiency of network DGPS technique in reducing the distance-dependent error in DGPS positioning.
\end{abstract}


Keywords:

Network-Based DGPS, Accuracy Assessment, Distance-Dependent Error

\section{Introduction}

As a fast-growing economic region in Malaysia required substantial activities to be undertaken, particularly in relation to marine activities such as navigation, hydrography, fishing industry, harbor fleet-management, and the oil and gas exploration. Therefore, these activities require a reliable augmentation positioning service based on GPS. Such a service could be provided by a Differential Global Positioning System (DGPS) technique that can be achieved 1 to 3 meters of positioning accuracy in real-time, hence providing safety of navigation to the user (Eskandarian, et al, 2019; Zhao, et al., 2016; Gary and Fly, 2008; Kaplan and Hegarty,2005).

Nevertheless, the DGPS accuracy is bound to distance-dependent error for instance ionospheric delay, tropospheric delay and radial orbital error (Przestrzelski \& Bakula, 2014; Musa, 2007). Previous study by Aris, 2017, due to ionospheric delay alone can reach up to $0.5 \mathrm{~m}$ for reference to rover stations separation of $274 \mathrm{~km}$ in Peninsular Malaysia. Therefore, network DGPS positioning is recommended to reduce the distance dependent error thus enhance the DGPS positioning accuracy (Bakula, 2010). The network-based DGPS is a commonly used in daily marine activities for instance the Wide area Augmentation System (WAAS), European Geostationary Navigation Overlay Service (EGNOS), Michibiki Satellite Augmentation System (MSAS) and etc. The International Association of Marine Aids to Navigation and Lighthouse Authorities (IALA) also recommend upgrading this DGPS technique with satellite augmentation system with network-based DGPS service (IALA, 2017).

Moreover, there are several interpolation methods has been introduced to model this GPS distance-dependent errors for generating the network correction such as Linear Interpolation Method (LIM), Distance-Based Linear Interpolation Method (DIM), Lease square collocation Method (LSC), and etc (Al-Shaery, et al., 2011; Dai, et al., 2003). This study utilized the LIM for network correction generation since the LIM provides the smallest noise for the correction terms compared to others interpolation method according to Shariff et al., 2014. In this paper, the network corrections are generated from Continuously Operating Reference Station (CORS) in Peninsular Malaysia and Sumatran Indonesia. Finally, the aforementioned SPP, DGPS and network-based DGPS technique are compared in detail as well as the advantages and disadvantages.

\section{Methodology}

This section describes the scope of the study, type of observation and method used to evaluate the performance accuracy of SPP, DGPS and network-based DGPS.

This study was conducted on west coast of Peninsular Malaysia starting from Senggarang to Jabatan Laut Malaysia Melaka (JLML) (see Figure 2). The observation utilized three (3) CORS and three (3) DGPS stations and was conducted on 15th August until 19th September 2018. 


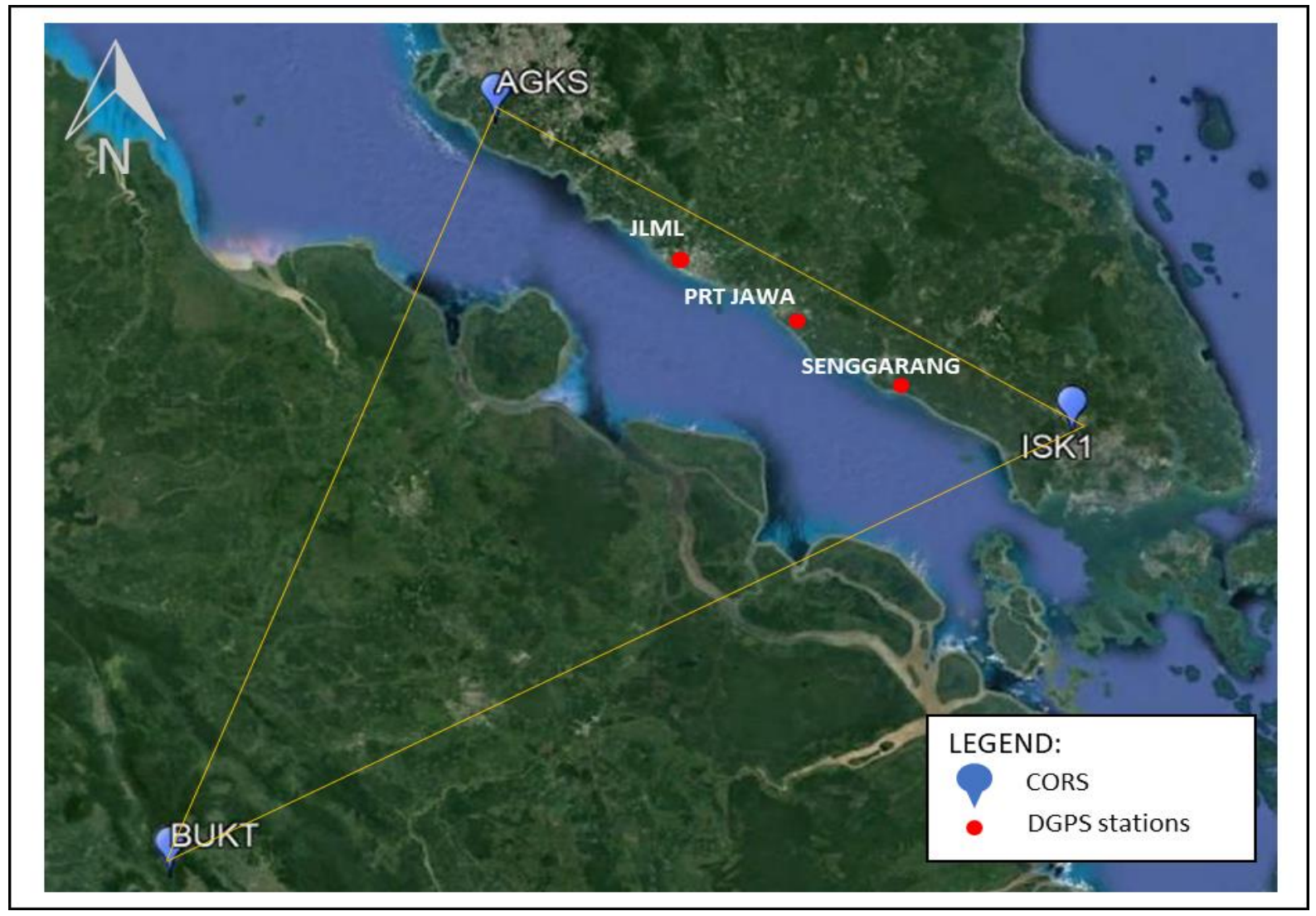

Figure 1: The Study Area.

The SPP, DGPS and network-based DGPS were computed manually via post-processing technique by using MATLAB environment. The process begins with computing the SPP for the targeted DGPS stations for comparison purposes. The pseudorange data ( $\mathrm{C} 1 \mathrm{code})$ are utilised to compute the SPP and DGPS which generally consist of multiple errors which can be derived as follows (Hofmann-Wellenhof et al., 2008);

$P_{i}^{k}(t)=\rho_{i}^{k}(t)+c\left[\delta_{i}(t)-\delta^{k}(t)\right]+I_{i}^{k}+T_{i}^{k}+d^{e p h}(t)+d_{i}(t)+d^{k}(t)+m_{i}(t)+\varepsilon_{i}^{k}$ (1)

where: $P_{i}^{k}(\mathrm{t})$ is the measured code pseudorange from satellite $k$ to station $i, \rho_{i}^{k}(t)$ - geometric range between the satellite $k$ (at transmit time) and the receiver $i$ (at receiver time), computed from ephemeris data and station coordinates; $\delta_{i}(t)$ - receiver clock error; $\delta^{k}(t)$ - satellite clock error; $I_{i}^{k}$ - measurement delay due to ionosphere; $T_{i}^{k}$ - measurement delay due to troposphere; $d^{e p h}(t)$ - effect of ephemeris error; $d_{i}(t)$ - receiver hardware delay; $d^{k}(t)$ - satellite hardware delay; $m_{i}(t)$-multipath; $\varepsilon_{i}^{k}$ - pseudorange measurement error. The right side of Eq.(1) can be written in simpler form;

$$
P_{i}^{k}(\mathrm{t})=\rho_{i}^{k}(t)+\Delta \rho_{i}^{k}(t)+\rho^{k}(t)+\rho_{i}(t)
$$

where; $\Delta \rho_{i}^{k}(t)$ is range biases due to radial orbital error and atmospheric refraction effects, $\rho^{k}(t)$ is purely satellite dependent, and $\rho_{i}(t)$ is purely receiver dependent. If station $k$ is $a$ 
known station, the pseudorange can be measured thus the pseudorange correction (PRC) can be calculated by:

$$
\begin{gathered}
P R C^{k}(\mathrm{t})=\rho_{i}^{k}(t)-P_{i}^{k}(t) \\
P R C^{k}(\mathrm{t})=-\Delta \rho_{i}^{k}(t)-\rho^{k}(t)-\rho_{i}(t)
\end{gathered}
$$

pseudorange correction, $P R C^{k}(\mathrm{t})=$ geometric distance (between satellite and reference station receiver $i), \rho_{i}^{k}(t)$ - pseudorange measured (between satellite $k$ and reference station receiver $i), P_{i}^{k}(t)$. The code pseudorange measured at the another GPS receiver (i.e., rover station) $j$ can be modelled by;

$$
P_{j}^{k}(\mathrm{t})=\rho_{j}^{k}(t)+\Delta \rho_{j}^{k}(t)+\rho^{k}(t)+\rho_{j}(t)
$$

The rover $j$ will be applying the $P R C^{k}(\mathrm{t})$ in Equation 4 to correct it pseudorange, and yields the corrected pseudorange, which can be expressed as;

$$
P_{j}^{k}(t)_{c o r r}=P_{j}^{k}(t)+P R C^{k}(\mathrm{t})
$$

In the case of the moderate distance (short baseline), satellite-receiver specific biases at both stations are highly correlated. Substituting Equation 4 and 5 into Equation 6 provides;

$$
P_{j}^{k}(t)_{c o r r}=\rho_{j}^{k}(t)+\left[\Delta \rho_{j}^{k}(t)-\Delta \rho_{i}^{k}(t)\right]+\Delta \rho_{j}(t)-\Delta \rho_{i}(\mathrm{t})
$$

Thus, the satellite dependent error is eliminated and the influences of satellite-receiver dependent errors are significantly reduced. This study utilised the AGKS CORS as reference station for all three (3) DGPS point in order to determine the effect of GPS distance-dependent error. Nevertheless, the distance-dependent error can be reduced by introducing the network correction or network PRC.

The network PRC can be generated by using the PRC from at least three (3) CORS and their known coordinate for specific rover location (i.e., virtual reference station PRC). The PRC of each CORS share the correlation plane of every satellite thus the PRC can be presented as the following equation (Bakula, 2006);

$$
\begin{aligned}
& a(t) x_{R e f 1}+b(t) y_{R e f 1}+c(t)=P R C_{R e f 1}(t) \\
& a(t) x_{R e f 2}+b(t) y_{R e f 2}+c(t)=P R C_{R e f 2}(t) \\
& a(t) x_{R e f 3}+b(t) y_{R e f 3}+c(t)=P R C_{R e f 3}(t)
\end{aligned}
$$

The factors $\mathrm{a}(\mathrm{t}), \mathrm{b}(\mathrm{t}), \mathrm{c}(\mathrm{t})$ are calculated for each epoch according to the matrix equation:

$$
\left[\begin{array}{l}
a(t) \\
b(t) \\
c(t)
\end{array}\right]=\left[\begin{array}{lll}
x_{R E F 1} & y_{R E F 1} & 1 \\
x_{R E F 2} & y_{R E F 2} & 1 \\
x_{R E F 3} & y_{R E F 3} & 1
\end{array}\right]^{-1}\left[\begin{array}{l}
P R C_{R E F 1}(t) \\
P R C_{R E F 2}(t) \\
P R C_{R E F 3}(t)
\end{array}\right]
$$


where $x_{R E F}, y_{R E F}$ are planar coordinates. For $\mathrm{n}$ reference stations, using the least-squares solution, the matrices A (design matrix) and L (observed minus calculated matrix) are as follows:

$$
\begin{gathered}
A=\left[\begin{array}{ccc}
x_{R E F 1} & y_{R E F 1} & 1 \\
\vdots & \vdots & \vdots \\
x_{R E F n} & y_{R E F n} & 1
\end{array}\right] \\
L^{T}=\left[\begin{array}{lll}
P R C_{R E F 1}(t) & \ldots & P R C_{R E F n}(t)
\end{array}\right]
\end{gathered}
$$

This mathematical model can be express as LIM which the PRC can be obtain directly by using the calculated factor. The pseudorange correction for virtual station (i.e., rover station) can be express as followed:

$$
P R C_{R E F V}(t)=a(t) x_{R o v}+b(t) y_{R o v}+c(t)
$$

where $x_{R o v}, y_{R o v}$ are the rover planar coordinates. Noted that all coordinate being used in the processing was in Universal Transverse Mercator (UTM) and all positioning method is utilising unity weight matrix for positioning computation. Overall processing procedures were illustrates in Figure 2 below:

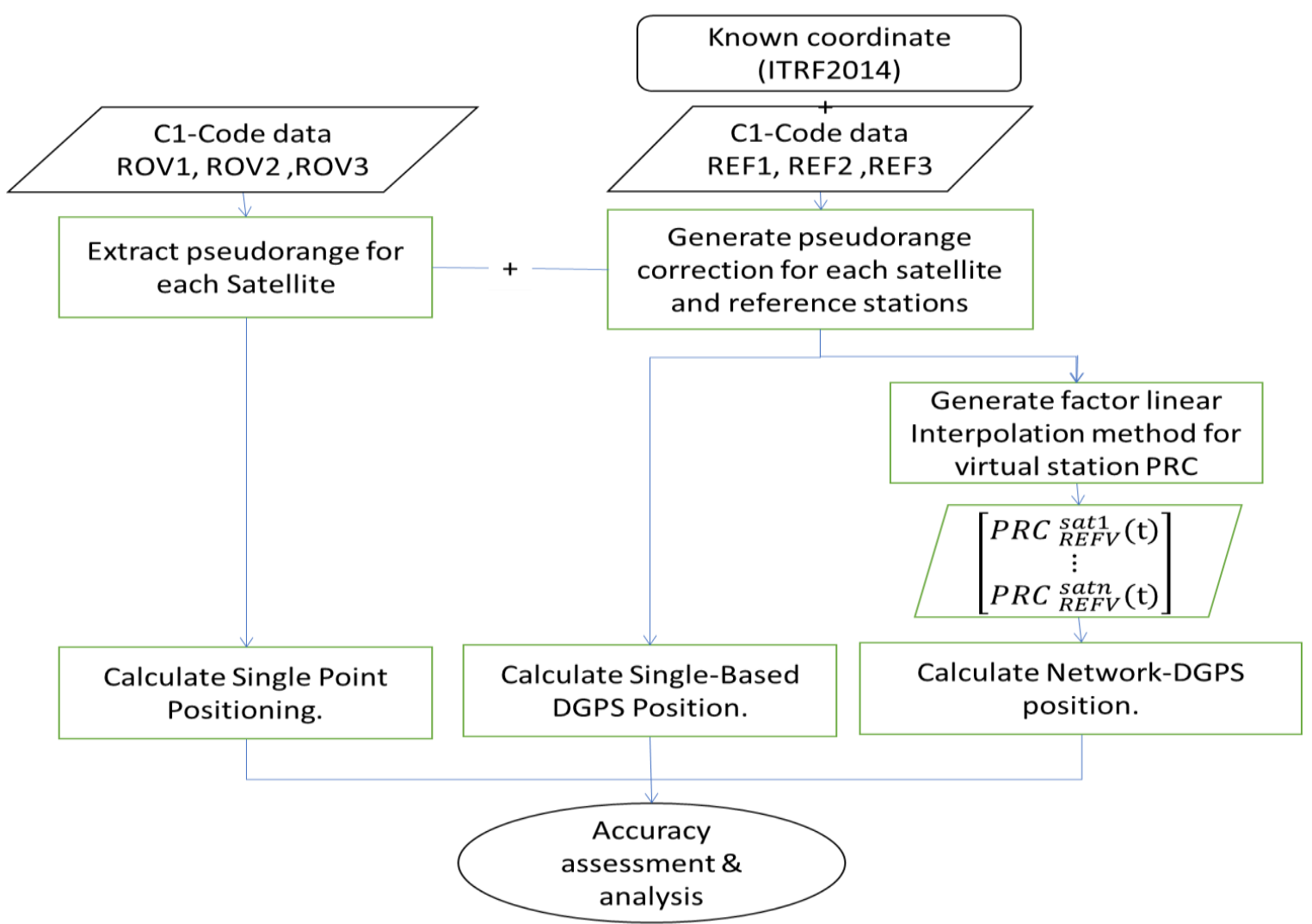

Figure 2: Procedure to Compute SPP, DGPS and Network-Based DGPS Positioning Technique. 


\section{Results}

The results from Figure 3 to Figure 5 illustrated the positioning accuracy by using three (3) positioning method which are SPP, DGPS and network-based DGPS. Each result consists of three differential parameters (i.e., X, Y and Z component). For the DGPS technique, the AGKS CORS was utilised as a reference station for all SGRG, PTJW and JLML DGPS stations.

The result on Figure 3 shows that when implementing the PRC into the DGPS, the accuracy was improved by $25 \mathrm{~m}$ for $\mathrm{Y}$ component, $8 \mathrm{~m}$ for $\mathrm{X}$ and $1 \mathrm{~m}$ for $\mathrm{z}$ component compared to SPP. Overall accuracy for SGRG station in DGPS was below than $5 \mathrm{~m}$. Network-based DGPS for SGRG station shows better accuracy when compared to SPP but lower compared to DGPS. The result also shows that the $\mathrm{X}$ and $\mathrm{Z}$ component were below than $5 \mathrm{~m}$ meanwhile the $\mathrm{Y}$ component was below than $15 \mathrm{~m}$.

The positioning accuracy on PTJW station (Figure 4) shows the lowest positioning accuracy for SPP with approximately $20 \mathrm{~m}$ error for $\mathrm{X}$ and $\mathrm{Y}$ component, while $8 \mathrm{~m}$ for $\mathrm{Z}$ component. On the other side, the DGPS result shows some improvement in accuracy which below than $15 \mathrm{~m}$ of accuracy. The network-based DGPS positioning for PTJW station shows insignificant improvement compared to SPP which the Y component was reduced around $5 \mathrm{~m}$ accuracy.

Next, the SPP for JLML station was below $5 \mathrm{~m}$ for $\mathrm{X}$ and $\mathrm{Y}$ component, while Y component was less than $15 \mathrm{~m}$. The DGPS positioning in this case shows significant improvement with all components were below than $3 \mathrm{~m}$ accuracy. Meanwhile, the network-based DGPS result also shows an improvement which $\mathrm{X}$ and $\mathrm{Y}$ component less than $3 \mathrm{~m}$, while $\mathrm{Y}$ component gradually decreasing below than $10 \mathrm{~m}$. 


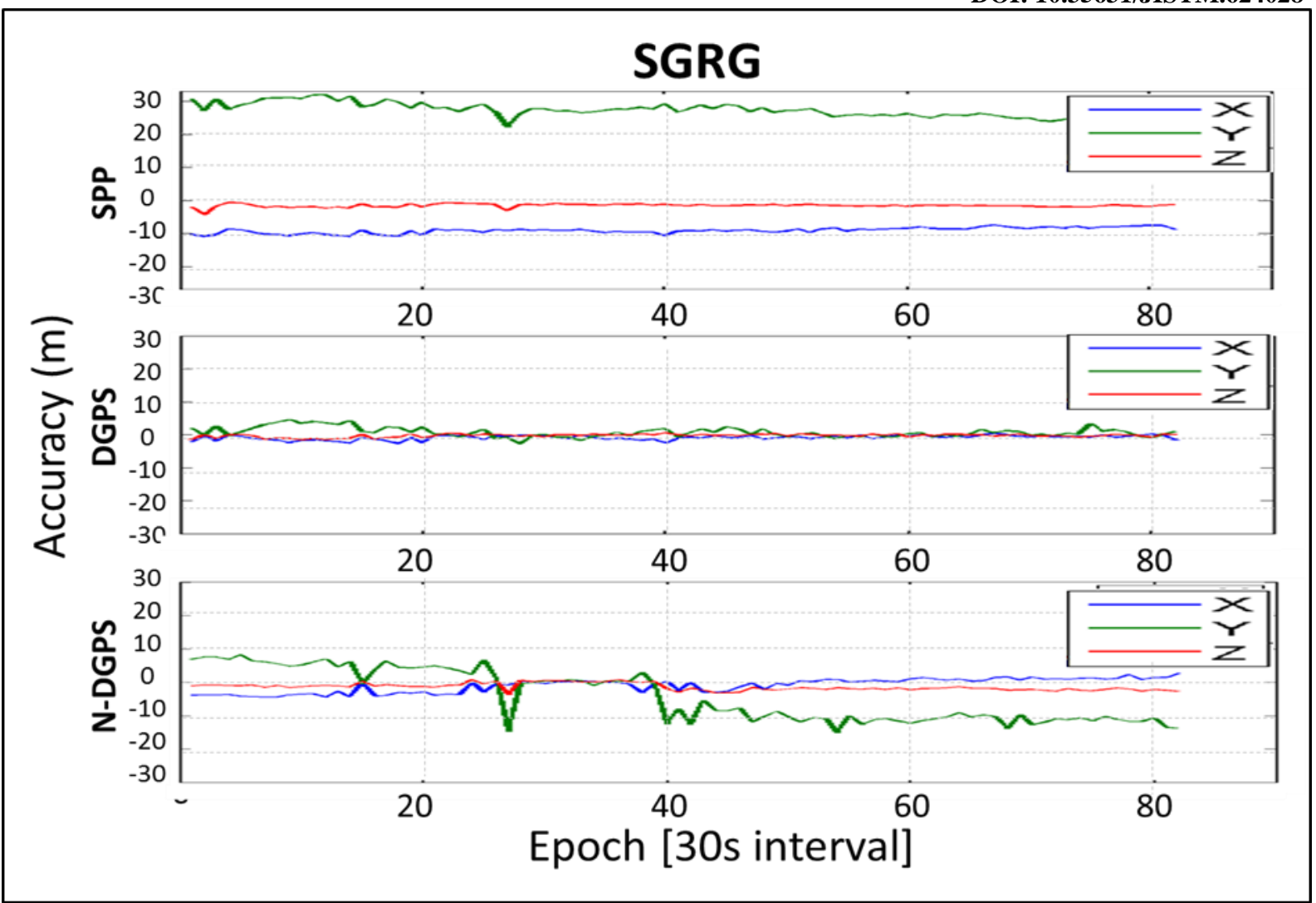

Figure 3: Positioning Accuracy of SPP, DGPS and Network-Based DGPS for SGRG Station.

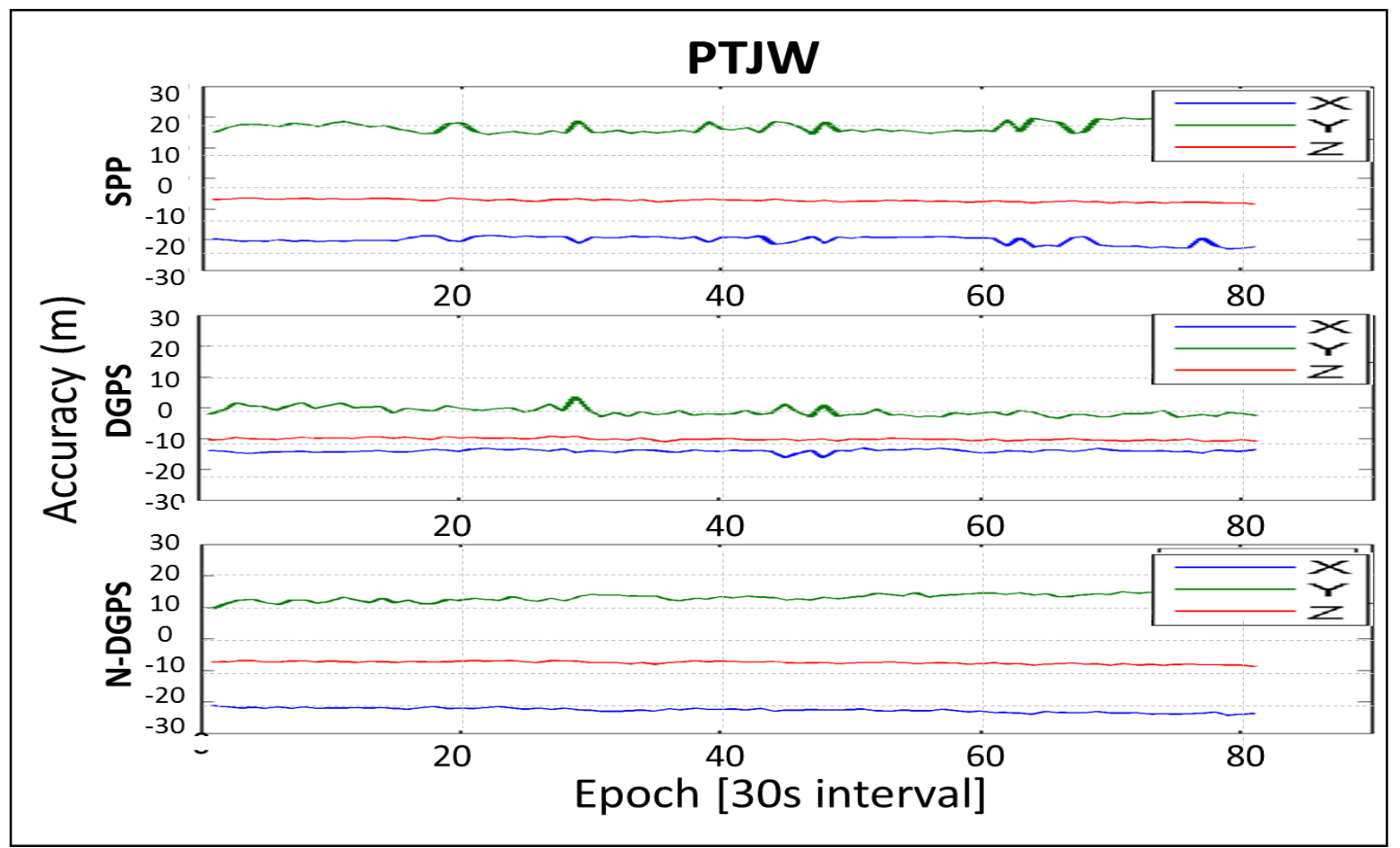

Figure 4: Positioning accuracy of SPP, DGPS and Network-Based DGPS for PTJW station. 


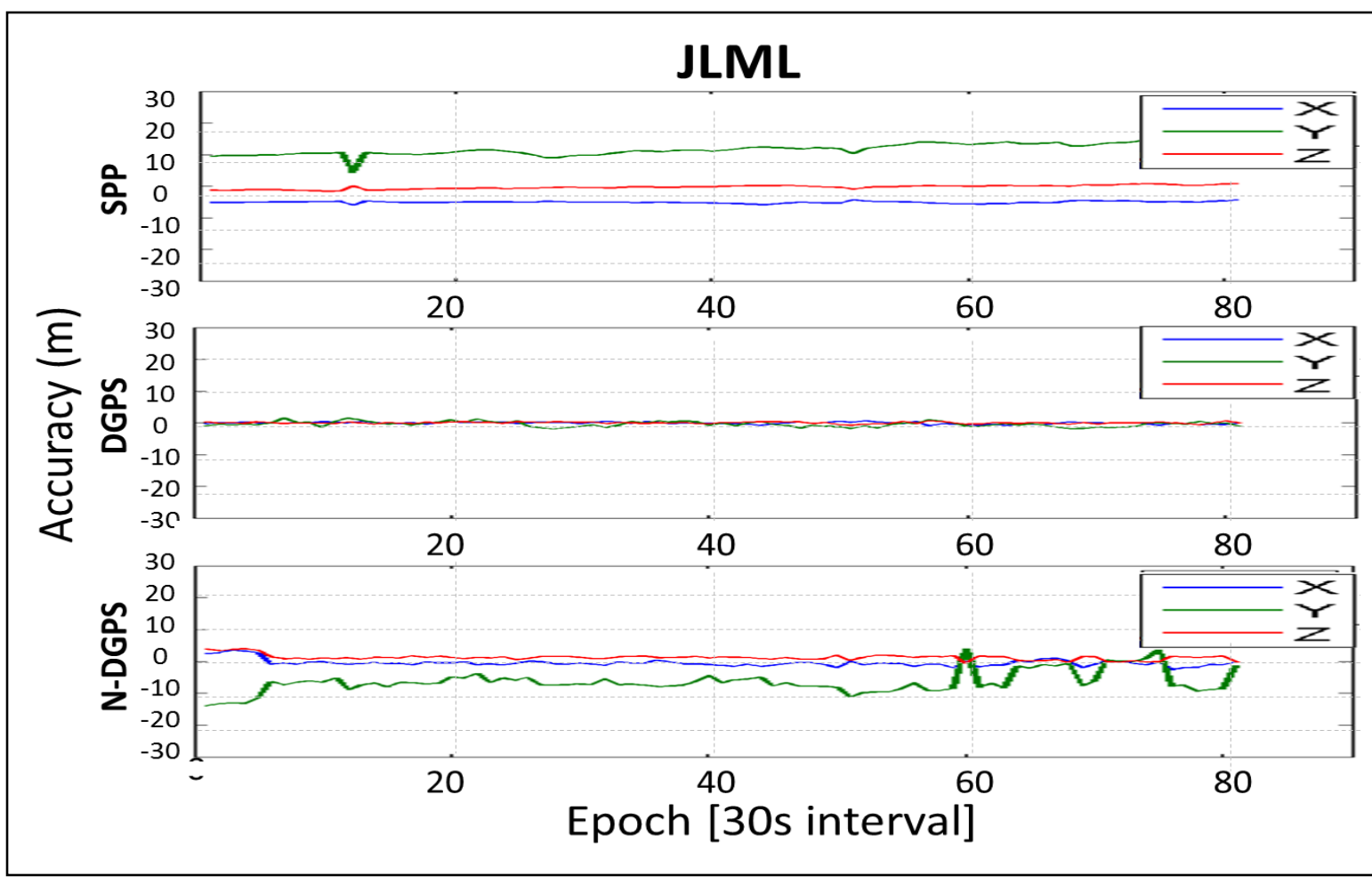

Figure 5: Positioning Accuracy of SPP, DGPS and Network-Based DGPS for JLML 


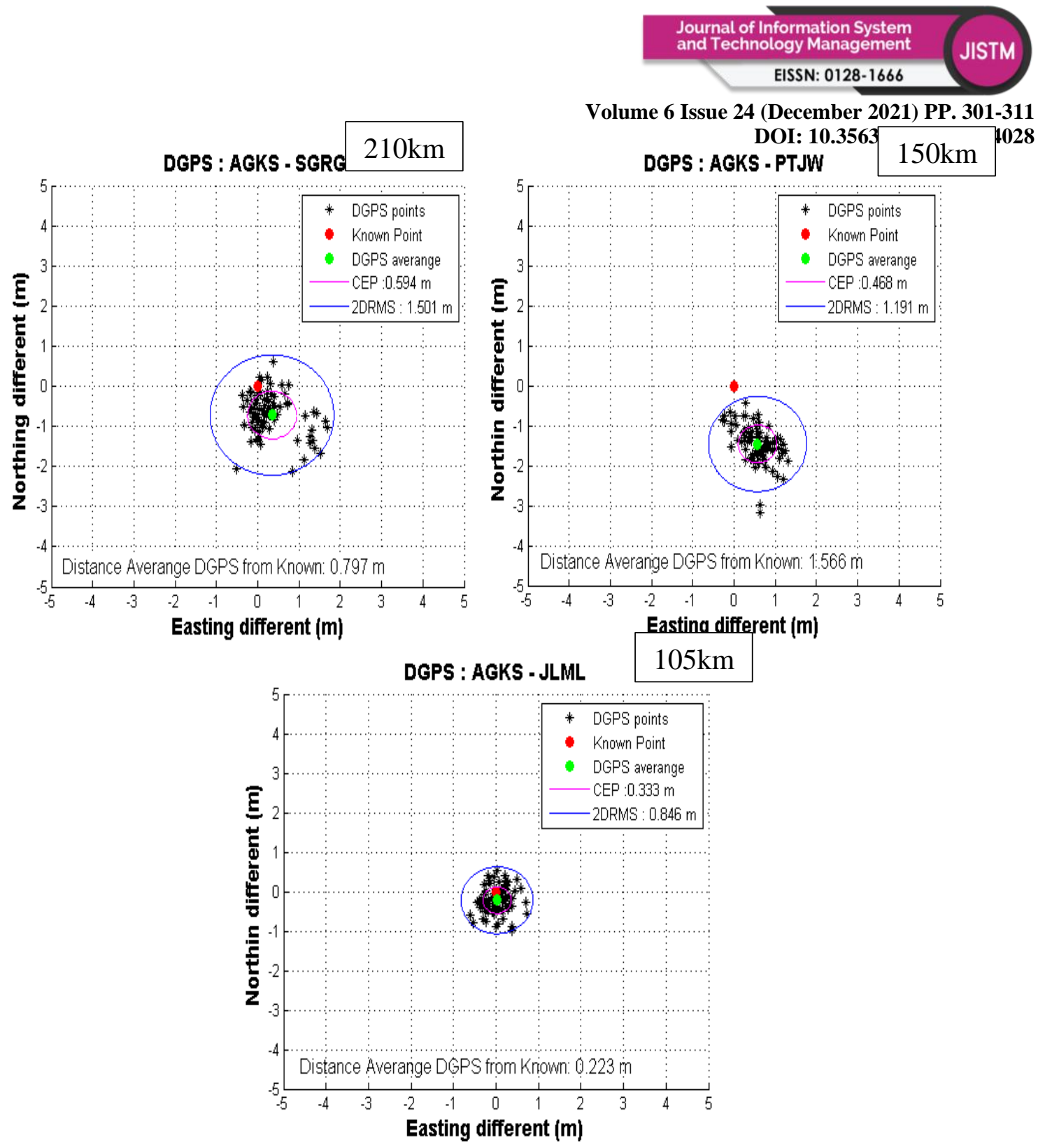

Figure 6: Positioning Twice-Distance Root Mean Square (2DRMS) and Circular Error Probability (CEP) Relative to Distance from Reference Station (AGKS).

Table 1: Positioning twice-Distance Root Mean Square (2DRMS) and Circular Error Probability (CEP) for DGPS positioning.

\begin{tabular}{ccccc}
\hline STATION & DISTANCE $(\mathbf{k m})$ & 2DRMS $(\mathbf{m})$ & CEP $(\mathbf{m})$ & ACCURACY $(\mathbf{m})$ \\
\hline JLML & 105 & 0.846 & 0.333 & 0.223 \\
PTJW & 150 & 1.191 & 0.468 & 1.566 \\
SGRG & 210 & 1.501 & 0.594 & 0.797 \\
\hline
\end{tabular}

Figure 6 and Table 1 shows that the twice-Distance Root Mean Square (2DRMS) and Circular Error Probability (CEP) are deteriorated when the distance separation became larger hence proven the distance dependence effect in DGPS positioning. In other word, the precision of the positioning is affected when the rover station located far from the reference station. Meanwhile, the accuracy at PTJW was inferior compared to SGRG which has greater distance separation from reference station. This is might due to site condition that consists of many obstructions Copyright $\odot$ GLOBAL ACADEMIC EXCELLENCE (M) SDN BHD - All rights reserved 
that could deteriorate the satellite signal quality. Nevertheless, the overall accuracy for all station can be considered reliable for marine safety of navigation purposed which below than $5 \mathrm{~m}$.

\section{Conclusion}

The DGPS technique is proven to have a superior positioning accuracy and reliability compared to SPP. The DGPS positioning show the significant results in proving the distance-dependent error which the 2DRMS and CEP were declining over the distance separation between rovers to reference station. On the other hand, the network-based DGPS could be enhanced by implementing the weighted matrix in the positioning computation.

Meanwhile, the network-based DGPS also have a better accuracy compared to SPP which around $10 \mathrm{~m}$ accuracy, but it is not achieved the requirable for safety of navigation which below than $5 \mathrm{~m}$. Further study on network-based DGPS could be conducted with additional rover point that scattered inside the designated network with additional observation time. Moreover, other interpolation method could be studied for generating the PRC in providing a better solution for the positioning. Larger study area is suggested for proving the distance dependent error more visible as a case study.

Finally, network-based DGPS algorithm in this study could be considered reliable when a vessel voyage on the open sea where there is none of DGPS reference station nearby, as it is accurate and reliable than SPP method. Critical condition like approaching a harbour, the network-based DGPS accuracy should be improvised and improved.

\section{Acknowledgement}

The authors would like to acknowledge the Research University Grant (RUG) vot number R.J130000.7352.4J341 for providing funding in this project. Special thanks to all Geomatic Innovation Research Group ( $\mathrm{GnG}$ ) members for their contribution in this study.

\section{References}

Al-Shaery, A., Lim, S., \& Rizos, C. (2011). Investigation of different interpolation models used in Network-RTK for the virtual reference station technique. Journal of Global Positioning Systems, 10(2), 136-148.

Aris, W. W., Musa, T. A., Ooi, W. H., Hairizam, A., Musliman, I. A., Othman, R., ... \& Abdullah, K. A. (2015). Spatial and seasonal ionospheric error growth in DGPS measurement: a case study in Malaysia. The Journal of Navigation, 68(6), 1105.

Bakuła, M. (2010). Network code DGPS positioning and reliable estimation of position accuracy. Survey Review, 42(315), 82-91.

Dai, L., Han, S., Wang, J., \& Rizos, C. (2003). Comparison of interpolation algorithms in network-basedGPS techniques. NAVIGATION, Journal of the Institute of Navigation, 50(4), 277-293.

Eskandarian, A., Wu, C., \& Sun, C. (2019). Research advances and challenges of autonomous and connected ground vehicles. IEEE Transactions on Intelligent Transportation System

Gary, P., \& Fly, C. E. (2008). NDGPS assessement final report. US Dept. Transp., Washington, DC, USA, Tech. Rep (2008). 
Hofmann-Wellenhof, B., lichtenegger, H., Collins, J. 2012. Global Positioning System: Theory and Practice.

IALA, 2017. G1129-The Retransmission of SBAS Corrections Using MF RadioBeacon and AIS. International Association of Marine Aids to Navigation and Lighthouse Authorities (IALA).

Karsky, D. 2004. Comparing Four Methods of Correcting GPS Data: DGPS, WAAS, L-Band,

Kaplan, E., \& Hegarty, C. (2005). Understanding GPS: Principles and Applications. Norwood, MA, USA: Artech House.

Musa, T. A. (2007). Analysis of residual atmospheric delay in the low latitude regions using network-based GPS positioning (Doctoral dissertation, University of New South Wales, Sydney, Australia).

Przestrzelski, P., \& Bakuła, M. (2014). Performance of real-time network code DGPS services of ASG-EUPOS in north-eastern Poland. Technical Sciences/University of Warmia and Mazury in Olsztyn, (17 (3)), 191-207.

Shariff, N. S., Musa, T. A., \& Othman, R. (2014). Evaluation of N-RTK interpolation with location-based dependency. Jurnal Teknologi, 71(4).

Yusup, A., Othman,R., Musliman,I.A., and Han, W. O. 2014. Iskandarnet CORS Network Integrity Monitoring.

Zhao, S., Chen, Y., \& Farrell, J. A. (2016). High-Precision Vehicle Navigation in Urban Environments Using an MEM's IMU and Single-Frequency GPS Receiver. IEEE Transactions on Intelligent Transportation Systems, vol. 17, no. 10, pp. 2854-2867. doi:10.1109/TITS.2016.2529000 